\title{
Isolation and Structure of Glucan from Regenerating Spheroplasts of Candida albicans
}

\author{
By P. GOPAL,${ }^{1}+$ P. A. SULLIVAN ${ }^{1}$ AND M. G. SHEPHERD ${ }^{2 *}$ \\ ${ }^{1}$ Department of Biochemistry, University of Otago, PO Box 56, Dunedin, New Zealand \\ ${ }^{2}$ Experimental Oral Biology Unit, School of Dentistry, PO Box 647, Dunedin, New Zealand
}

(Received 7 October 1983, revised 21 December 1983)

\begin{abstract}
Regenerating spheroplasts of Candida albicans formed organized glucan nets in liquid culture. The nets consisted of interwoven microfibrils about $50 \mathrm{~nm}$ wide, but of an undetermined length. Partial acid hydrolysis of the polysaccharide showed the presence of chains of $\beta(1 \rightarrow 3)$ - and $\beta(1 \rightarrow 6)$-linked glucose residues, but no intrachain $\beta(1 \rightarrow 3)$ and $\beta(1 \rightarrow 6)$ linkages. Periodate oxidation and GLC of the methylated glucan indicated a highly branched polymer $(9.5 \%$ branch points). Sequential enzymic degradation of the isolated nets confirmed the presence of chains of $\beta(1 \rightarrow 3)$ - and $\beta(1 \rightarrow 6)$-linked glucose residues. Degradation by $(1 \rightarrow 3)-\beta$ - and $(1 \rightarrow 6)$ - $\beta$-glucanase released $23 \%(\mathrm{w} / \mathrm{w})$ and $30 \%(\mathrm{w} / \mathrm{w})$ respectively of the carbohydrate as glucose equivalents. The residual material was degraded by chitinase. Equal amounts of $N$-acetylglucosamine and glucose equivalents were detected in the chitinase hydrolysate, suggesting a possible linkage between glucan and chitin. Our data indicate that the cell wall of $C$. albicans contains at least two highly branched glucans with predominantly $\beta(1 \rightarrow 3)$ or $\beta(1 \rightarrow 6)$ linkages.
\end{abstract}

\section{INTRODUCTION}

Candida albicans is an opportunistic human pathogen which exhibits dimorphism. Transition from the yeast to the mycelial form is accompanied by changes in cell wall architecture and composition (Cassone et al., 1979; Sullivan et al., 1983). The fungal wall represents the most obvious difference between pathogen and host cell, both of which are eukaryotic; hence, the wall is a potential target for antifungal agents. Changes in wall glucans during growth result in the appearance of polyene resistance (Cassone et al., 1979). There are only two reports on the nature of C. albicans wall glucans (Bishop et al., 1960; Yu et al., 1967), and these indicated a predominance of $\beta(1 \rightarrow 6)$ linkages. However, the glucan isolated was the alkali soluble fraction which is a minor component $(<20 \%)$ of the total glucan (Sullivan et al., 1983). We have recently described the metabolism of spheroplasts of $C$. albicans during wall regeneration (Gopal et al., 1984). In this communication we describe the analysis of the glucan fraction isolated from regenerating spheroplasts.

\section{METHODS}

Organism and culture conditions. Candida albicans ATCC 10261 was used throughout this work. It was propagated and maintained on malt extract agar slopes. Yeast cells of $C$. albicans ATCC 10261 were prepared in shake culture using glucose as the carbon source as previously described (Shepherd \& Sullivan, 1976). Midexponential phase cells $(16-18 \mathrm{~h})$ were harvested and washed by centrifugation. These cells were used throughout the study and are referred to as intact yeast cells.

Chemicals. Lyticase preparation was purified from culture supernatants of Oerskovia xanthionolytica by a procedure based on that described by Scott \& Schekman (1980). Zymolyase 5000 was purchased from Kirin Brewery Co., Takasaki, Japan. $\alpha$-Amylase (from human saliva), pancreatin, chitinase and gentiobiose were purchased from Sigma. Laminarin was obtained from the US Biochemical Corp., Cleveland, Oh., USA. Pustulan

† Present address: Department of Biochemistry, University of California, Berkeley, Calif. 94720, USA. 
was from Calbiochem. Endo-( $1 \rightarrow 6)-\beta$-glucanase was a gift from Dr E. T. Reese, US Army Laboratories, Natick, Mass., USA. Laminara-oligosaccharides and laminaribiose were gifts from Dr R. J. Sturgeon, Herriot-Watt University, Edinburgh, UK. 2,3,4,6-Tetra- $O$-methylglucose was purchased from Koch-Light. D-[U-14 $\mathrm{C}] \mathrm{Glucose}$ $\left(230 \mathrm{mCi} \mathrm{mmol}^{-1} ; 8.51 \mathrm{GBq} \mathrm{mmol}^{-1}\right.$ ) was obtained from Amersham.

Regeneration of spheroplasts. Spheroplasts were prepared from yeast cells as described by Poulter et al. (1981) using the lyticase from $O$. xanthionolytica, and were regenerated in $5.0 \mathrm{mM}$-glucose for $6 \mathrm{~h}$ by the procedure of Gopal et al. (1984). For the analysis by enzymic hydrolysis (see below), spheroplasts $\left(8 \times 10^{7}\right)$ were regenerated for $6 \mathrm{~h}$ at $35^{\circ} \mathrm{C}$ with $\left[{ }^{14} \mathrm{C}\right]$ glucose $(3 \mu \mathrm{Ci})$ in $20 \mathrm{ml} 0.5 \mathrm{M}-\mathrm{MgSO}_{4}$ containing $0.1 \mathrm{M}-\mathrm{Tris} / \mathrm{HCl}, \mathrm{pH} 7 \cdot 2$.

Isolation and purification of glucan from regenerated spheroplasts. The regenerated spheroplasts were harvested by centrifugation and washed once with distilled water. The cells were resuspended in distilled water, together with $0.5 \mathrm{~mm}$ glass beads $(1: 2: 2, \mathrm{w} / \mathrm{v} / \mathrm{w})$. A cell-free extract was obtained by shaking the mixture at 4000 r.p.m. in a Braun homogenizer (B. Braun, Melsungen AG, FRG). The homogenate was filtered through a sintered glass funnel and the beads were washed free of any residual material with distilled water. The combined filtrates were centrifuged ( 3000 r.p.m.) to recover the wall fraction, which was purified by a modification of the procedure described by Kreger \& Kopecká (1975). The washed pellet was resuspended in $0 \cdot 1 \mathrm{M}$-phosphate buffer, pH $7 \cdot 2$, containing $0.02 \%$ sodium azide and chloramphenicol $\left(5 \mu \mathrm{g} \mathrm{ml}^{-1}\right)$. This suspension was incubated with $1 \%(\mathrm{w} / \mathrm{v})$ trypsin at $37^{\circ} \mathrm{C}$ for $12 \mathrm{~h}$. After washing with distilled water, the pellet was extracted with chloroform/methanol $(2: 1, v / v)$ on a gyrotary shaker $(200$ r.p.m. $)$ at $37^{\circ} \mathrm{C}$ for $6 \mathrm{~h}$. The glucan nets were then washed with $95 \%(\mathrm{v} / \mathrm{v})$ ethanol and, finally, with hot water to remove traces of cytoplasmic contamination. The purified glucan nets were lyophilized and stored at $-20^{\circ} \mathrm{C}$.

Electron microscopy. An aqueous suspension of the purified glucan nets was placed on carbon-coated copper grids $(3.50 \mathrm{~mm} ; 300 / 75 \mathrm{mesh})$. After drying, the specimens were negatively stained in a $5 \%(\mathrm{w} / \mathrm{v})$ uranyl acetate solution for $30 \mathrm{~min}$ and examined under a Siemens 102 electron microscope.

Chemical and structural analysis of glucan nets : total acid hydrolysis. Isolated glucan (20 mg) was treated with $90 \%$ $(\mathrm{v} / \mathrm{v})$ formic acid $(0.5 \mathrm{ml})$ at $100^{\circ} \mathrm{C}$ for $1 \mathrm{~h}$. The formic acid was then evaporated under vacuum and total acid hydrolysis was done by refluxing the residue with $2.5 \mathrm{M}-\mathrm{H}_{2} \mathrm{SO}_{4}(5 \mathrm{ml})$ at $100^{\circ} \mathrm{C}$ for $4 \mathrm{~h}$. Solid $\mathrm{BaCO}_{3}$ was added under nitrogen to neutralize the hydrolysate. The $\mathrm{BaSO}_{4}$ was removed by filtration and the excess $\mathrm{Ba}^{2+}$ ions were removed with Dowex $50-\mathrm{H}^{+}$. Monosaccharides were separated as their alditol peracetate derivatives (Borchardt \& Piper, 1970). For the GLC identification of alditol acetates, standards were prepared from rhamnose, xylose, arabinose, galactose, mannose, glucose, fucose and myoinositol.

Methylation analysis. Freeze-dried glucan nets $(20 \mathrm{mg})$ were reduced by an aqueous suspension (10 ml) of sodium borohydride $(50 \mathrm{mg})$ for $4 \mathrm{~h}$ at $18^{\circ} \mathrm{C}$. Excess sodium borohydride was removed by adding Dowex $50-\mathrm{H}^{+}$resin to give a $\mathrm{pH}$ value of 3-4, the suspension was filtered and the filtrate was concentrated to dryness. Methanol (10 $\mathrm{ml})$ was added and the suspension was dried for $15 \mathrm{~min}$ at $105^{\circ} \mathrm{C}$. The dried material was placed in a $100 \mathrm{ml}$ roundbottomed three-necked flask with a condenser, a rubber septum cap and an inlet for nitrogen. Dimethyl sulphoxide $(20 \mathrm{ml})$ was added, dry nitrogen was passed through the flask, and the suspension was stirred with a magnetic stirrer. The flask was incubated in an ultrasonic bath at $70^{\circ} \mathrm{C}$ overnight to facilitate the complete dissolution of the material. The polysaccharide was then treated with dimsyl ion prepared according to the procedure of Conrad (1972). The methylation reaction was done by the procedure of Hakamori (1964) as modified by Bouveng \& Lindberg (1965). Three methylations were done on each sample, and the reaction was monitored by the loss of hydroxyl absorption at $3200-3500 \mathrm{~nm}$ in a Perkin-Elmer 421 grating infra-red spectrophotometer. The methylated material was insoluble in aqueous solutions and was therefore treated with $90 \%(\mathrm{v} / \mathrm{v})$ formic acid $(10 \mathrm{ml})$ at $100^{\circ} \mathrm{C}$ for $1 \mathrm{~h}$. Excess acid was removed under vacuum. The residue was suspended in distilled water and then taken to dryness. This material was hydrolysed with $0.13 \mathrm{M}-\mathrm{H}_{2} \mathrm{SO}_{4}(10 \mathrm{ml})$ at $100{ }^{\circ} \mathrm{C}$ for $16 \mathrm{~h}$. The neutralized hydrolysates were converted to the alditol peracetate derivatives as described by Borchardt $\&$ Piper (1970).

Periodate oxidation. Aqueous suspensions of the glucan nets, laminarin, pustulan and glycogen ( $15 \mathrm{mg}$ ) were treated with sodium metaperiodate (final concentration $0.13 \mathrm{M}$ ) at $4{ }^{\circ} \mathrm{C}$ in the dark. Oxidation was monitored at $222.5 \mathrm{~nm}$ (Aspinall \& Ferrier, 1957), and the formic acid produced was determined by titration with sodium hydroxide (Hay et al., 1965).

Partial acid hydrolysis. Partial acid hydrolysates of the regenerated glucan nets, glycogen, laminarin and pustulan were prepared by the method of Peat et al. (1958). Samples of each glucan (10 mg) were heated with $0.12 \mathrm{ml}$ of $90 \%(\mathrm{v} / \mathrm{v})$ formic acid in stoppered round-bottomed flasks at $100{ }^{\circ} \mathrm{C}$. After $25 \mathrm{~min}$, a further $0.04 \mathrm{ml}$ of $90 \%(\mathrm{v} / \mathrm{v})$ formic acid was added and each mixture was heated for another $15 \mathrm{~min}$. The formic acid was removed by rotary evaporation, $1.5 \mathrm{ml} 0.44 \mathrm{M}-\mathrm{H}_{2} \mathrm{SO}_{4}$ was added, and the resulting suspension was again treated for $90 \mathrm{~min}$ at $100{ }^{\circ} \mathrm{C}$. The hydrolysates so obtained were neutralized and deionized with Dowex $50-\mathrm{H}^{+}$. The oligomers from each polysaccharide were separated on paper chromatograms using the following solvent systems: A, ethyl acetate/pyridine/water (10:4:3, by vol.); B, butanol/pyridine/water $(6: 4: 3$, by vol.); C, propanol/ethyl acetate/water $(7: 1: 3$, by vol.). Components were identified by silver staining (Dawson et al., 1959).

Sequential enzymic hydrolysis. The isolated ${ }^{14} \mathrm{C}$-labelled glucan nets from C. albicans were incubated sequentially 
with specific glucan hydrolases. Each incubation was carried out in a gyrotary shaker at 200 r.p.m. The buffers used were supplemented with $0 \cdot 02 \%(\mathrm{w} / \mathrm{v})$ sodium azide and chloramphenicol $\left(50 \mu \mathrm{g} \mathrm{ml}^{-1}\right)$ to avoid bacterial contamination and each incubation mixture had a final volume of $2.0 \mathrm{ml}$. Glucan $(10 \mathrm{mg})$ was suspended in $50 \mathrm{~mm}$-phosphate buffer (pH 6.9) containing $5.0 \mathrm{~mm}-\mathrm{NaCl}$, and incubated with amylase from human saliva (4 mg) for $12 \mathrm{~h}$ at $30^{\circ} \mathrm{C}$. The supernatant was separated by centrifugation; the pellet was washed once, resuspended in $0.2 \mathrm{M}$-sodium acetate buffer ( $\mathrm{pH} \mathrm{5.4)}$ and incubated with a mixture of endo- and exo-( $\rightarrow 3)$ - $\beta$-glucanase (Zymolyase) $(10 \mathrm{mg})$ for $24 \mathrm{~h}$ at $37^{\circ} \mathrm{C}$. The residue from the Zymolyase incubation, after one wash in acetate buffer, was resuspended in $50 \mathrm{~mm}$-citrate buffer $(\mathrm{pH} \mathrm{4.5)}$ and incubated with $(1 \rightarrow 6)$ - $\beta$-endoglucanase $(10 \mathrm{mg})$ for $24 \mathrm{~h}$ at $37^{\circ} \mathrm{C}$. Finally, the $(1 \rightarrow 6)-\beta$-glucanase-resistant material was suspended in $0 \cdot 1 \mathrm{M}$-phosphate buffer, pH 6 , and treated with chitinase $(5 \mathrm{mg})$ at $30^{\circ} \mathrm{C}$ for a further $12 \mathrm{~h}$. The supernatants from each enzyme incubation were combined with the washings and analysed for radioactivity and carbohydrate (Dubois et al., 1956). $N$ Acetylglucosamine was estimated by the method of Reissig et al. (1955).

\section{RESULTS}

\section{Electron microscopy of C. albicans glucan}

Purified glucan from regenerated spheroplasts exhibited an organized net structure when examined under the electron microscope. Fig. 1 shows an electron micrograph of a negatively stained, cleaned, fibrillar glucan net. The rope-like strands forming the nets appeared to be composed of interwoven microfibrils (inset of Fig. 1). It was difficult to measure the thickness of individual microfibrils as they aggregated to form bundles of varying thickness (Fig. 1). Also, the length of these fibrils could not be estimated since in a net structure it is not possible to trace the microfibril from one end to the other.

\section{Chemical analysis of glucan nets}

Total acid hydrolysis. The monosaccharide composition of the glucan was determined by preparing a total acid hydrolysate of the glucan. Glucose, mannose and arabinose were the only

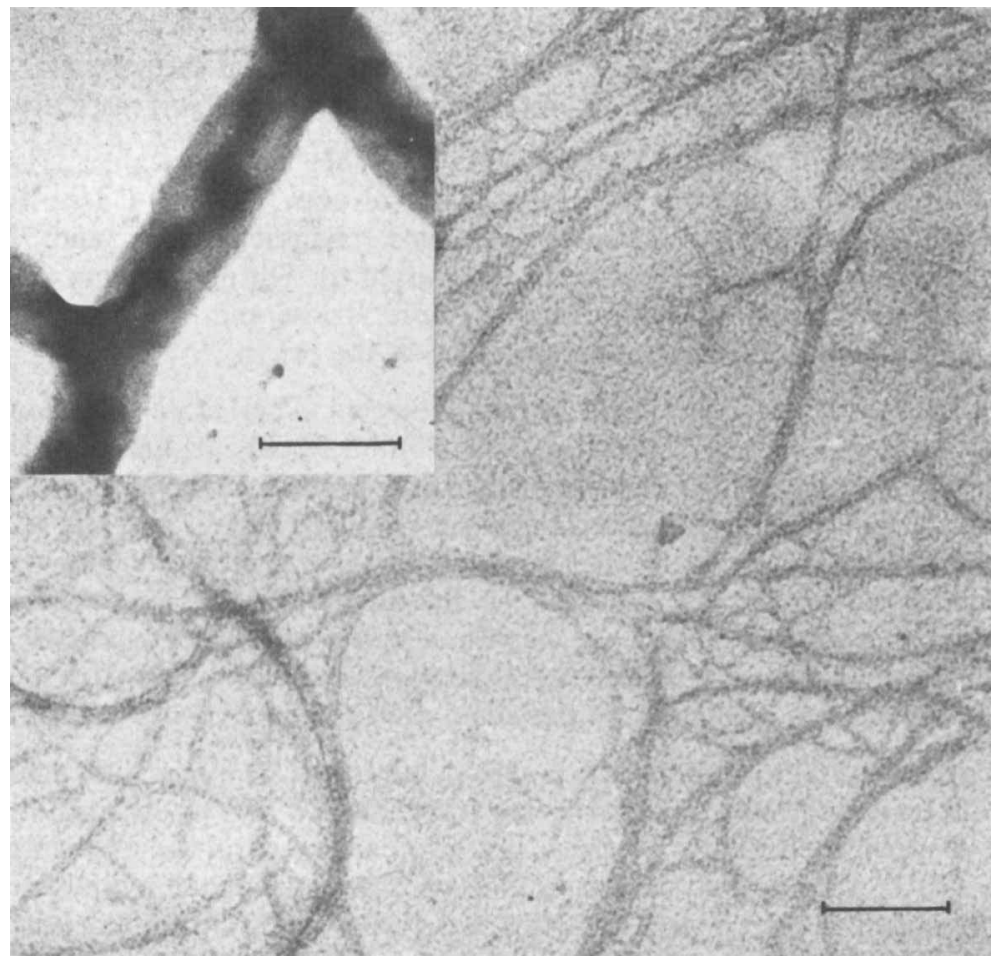

Fig. 1. Fibrillar nets formed by regenerated $C$. albicans spheroplasts. The isolated nets, purified as described in Methods, were negatively stained with uranyl acetate for $30 \mathrm{~min}$ and viewed under a Siemens 102 transmission electron microscope. The bar marker represents $0 \cdot 5 \mu \mathrm{m}(0 \cdot 1 \mu \mathrm{m}$ in the inset). 
Table 1. Analysis of the total acid hydrolysate from glucan nets

Alditol acetates of total acid hydrolysates were separated by GLC on a $3 \%$ ECNSS-M column and the percentage composition was determined from the area under the peaks. The data for laminarin are from Ram et al. (1981).

$\begin{array}{lcc}\text { Component } & \overbrace{\text { Glucan }}^{\text {Percentage composition }} \\ \text { Glucose } & 88.4 & 94.0 \\ \text { Mannose } & 9.2 & 2.8 \\ \text { Xylose } & 0.0 & 3.0 \\ \text { Arabinose } & 2.4 & 0.0\end{array}$

Table 2. Periodate oxidation of glucans

The conditions for the periodate oxidation of the glucans were as described in Methods. The data are not corrected for non-glucose constituents present in the polysaccharides. The values reported for formic acid production and periodate consumption are, therefore, mol per mol anhydrohexose.

\begin{tabular}{cccc}
$\begin{array}{c}\text { Time } \\
\text { (h) }\end{array}$ & $\begin{array}{c}\text { C. albicans } \\
\text { glucan }\end{array}$ & $\begin{array}{c}\text { Pustulan } \\
\text { Laminarin }\end{array}$ & Formic acid production \\
& \multicolumn{3}{c}{0.00} \\
0 & 0.00 & 0.00 & 0.1 \\
24 & 0.29 & 0.81 & 0.14 \\
48 & 0.37 & 0.93 & 0.14 \\
96 & 0.39 & 0.93 & 0.26 \\
& & Periodate consumption
\end{tabular}

sugars found in the hydrolysate. Glucose was the major product and accounted for $88.4 \%$ of the total monosaccharides; mannose and arabinose contributed 9.2 and $2.4 \%$ respectively (Table 1 ).

Partial acid hydrolysis. Partial acid hydrolysates from the $C$. albicans glucan, laminarin and pustulan were analysed by paper chromatography in solvents A, B and C (see Methods). For positive identification of the oligomers, standard oligosaccharides and disaccharides (gentiobiose and laminaribiose) were also chromatographed. The glucan from C. albicans gave the following di- and oligosaccharides: laminari-biose, -triose and -tetrose; gentio-biose and -triose, and unidentified oligomers which remained at the origin.

Periodate oxidation. The $C$. albicans glucan was subjected to periodate oxidation as were two other glucans of known structure : laminarin, a $\beta(1 \rightarrow 3)$-linked polymer and pustulan, a $\beta(1 \rightarrow 6)$ linked polymer. The amount of periodate consumed and formic acid produced was measured for each glucan at different time intervals. Each glucan produced formic acid and after $48 \mathrm{~h}$ there was no further acid production (Table 2). The C. albicans glucan produced $0.37 \mathrm{~mol}$ formic acid per mol anhydroglucose; this was greater than the amount of acid produced by laminarin $(0.14 \mathrm{~mol}$ per mol anhydrohexose), but less than the acid produced by pustulan $(0.93 \mathrm{~mol}$ per mol anhydrohexose). As with acid production, $C$. albicans glucan consumed more periodate than laminarin and pustulan consumed more periodate than the other two glucans (Table 2).

Methylation analysis. Glucan, laminarin and pustulan from C. albicans were methylated three times using the modified Hakamori procedure (Hakamori, 1964) to obtain fully methylated glucan. The $O$-methylated alditol acetates, produced after hydrolysis of each glucan, were separated by GLC. After hydrolysis, the $C$. albicans glucan yielded $O$-methyl alditol acetates which were identified as 2,3,4,6-tetra- $O$-methyl, 2,3,4-tri- $O$-methyl, 2,4,6-tri- $O$-methyl and 2,4di-O-methyl derivatives of glucose (Table 3 ). Pustulan yielded only one major peak identified as 2,3,4-tri- $O$-methylglucose $(87 \%)$, a minor peak of $2,3,4,6$-tetra- $O$-methylglucose $(10 \%)$; and a trace amount of 2,4-di- $O$-methylglucose (Table 3). 
Table 3. Composition of the hydrolysates of permethylated glucans following acetylation

The peaks were identified from GLC retention times and also by adding authentic standards to the sample. The percentage composition was determined by making five copies of the GLC traces, cutting each peak and weighing it. The weights of all peaks were added and individual percentages calculated. The molar ratios were calculated from the percentage composition data.

\begin{tabular}{llcc}
$\begin{array}{l}O \text {-Methyl D-glucitol } \\
\text { acetate derivative }\end{array}$ & \multicolumn{1}{c}{ Type of linkage } & $\begin{array}{c}\text { Percentage } \\
\text { composition }\end{array}$ & $\begin{array}{c}\text { Molar } \\
\text { ratio }\end{array}$ \\
$\begin{array}{l}C \text { albicans glucan } \\
\text { 2,3,4,6-Tetra- } O-\end{array}$ & $\begin{array}{l}\text { Non-reducing end group } \\
\text { 2,4,6-Tri- } O-\end{array}$ & $9 \cdot 5$ & $1 \cdot 2$ \\
2,3,4-Tri- $O-$ & $(1 \rightarrow 3)$ & $46 \cdot 6$ & $5 \cdot 3$ \\
2,4-Di- $O-$ & $(1 \rightarrow 6)$ & $29 \cdot 9$ & $3 \cdot 4$ \\
4,6-Di- $O-$ & Branch point C-1, C-3, C-6 & $9 \cdot 5$ & $1 \cdot 0$ \\
Pustulan & Branch point C-1, C-2, C-3 & $4 \cdot 5$ & $0 \cdot 4$ \\
2,3,4,6-Tetra- $O-$ & & & \\
2,3,4-Tri- $O-$ & Non-reducing end group & $10 \cdot 5$ & $5 \cdot 1$ \\
2,4-Di- $O-$ & $(1 \rightarrow 6)$ & $87 \cdot 1$ & $39 \cdot 2$ \\
Laminarin & Branch point C-1, C-3, C-6 & $2 \cdot 4$ & $1 \cdot 0$ \\
2,3,4,6-Tetra- $O-$ & & & \\
2,4,6-Tri- $O-$ & Non-reducing end group & $7 \cdot 6$ & $1 \cdot 23$ \\
2,4-Di- $O-$ & $(1 \rightarrow 3)$ & $79 \cdot 3$ & $11 \cdot 9$ \\
4,6-Di- $O-$ & Branch point C-1, C-3, C-6 & $7 \cdot 2$ & $1 \cdot 0$ \\
& Branch point C-1, C-2, C-3 & $6 \cdot 5$ & $0 \cdot 9$
\end{tabular}

Table 4. Sequential enzymic hydrolysis of C. albicans glucan

C. albicans glucan isolated from spheroplasts regenerated with $\left[{ }^{14} \mathrm{C}\right]$ glucose was sequentially degraded with the enzymes listed as described in Methods. The supernatants from each incubation were analysed for radioactivity and carbohydrate content with appropriate controls. The carbohydrate analysed $(2.8 \mathrm{mg})$ had a total activity of 126000 c.p.m.

\begin{tabular}{|c|c|c|c|c|}
\hline \multirow[b]{2}{*}{ Enzyme } & \multirow[b]{2}{*}{$\begin{array}{l}\text { Radioactivity } \\
\text { (c.p.m.) }\end{array}$} & \multicolumn{2}{|c|}{ Sugar produced } & \multirow[b]{2}{*}{$\begin{array}{l}\text { Specific activit } \\
\text { (c.p.m. } \mathrm{mg}^{-1} \text { ) }\end{array}$} \\
\hline & & $\overbrace{(\mathrm{mg})}$ & $(\%)$ & \\
\hline$\alpha$-Amylase & 980 & Nil & - & - \\
\hline Zymolyase & 57146 & 0.65 & 23 & 94456 \\
\hline Additional zymolyase & 650 & Nil & - & - \\
\hline$(1 \rightarrow 6)-\beta$-Glucanase & 13475 & 0.85 & 30 & 15815 \\
\hline \multirow[t]{2}{*}{ Chitinase } & $51903^{*}$ & $0.52 \dagger$ & 19 & \\
\hline & & $0.58 \ddagger$ & 21 & \\
\hline
\end{tabular}

With laminarin, the major peak was 2,4,6-tri-O-methylglucose $(79 \cdot 3 \%)$. The minor peaks were 2,3,4,6-tetra-O-methyl $(7 \cdot 6 \%)$ and 2,4-di-O-methyl $(7 \cdot 2 \%)$ derivatives (Table 3$)$. A peak with a retention time corresponding to that of 4,6-di-O-methylglucose was also identified in the laminarin and $C$. albicans glucan hydrolysates.

\section{Analysis of glucan structure by sequential enzymic hydrolysis}

The ${ }^{14} \mathrm{C}$-labelled glucan nets were subjected to sequential incubation with hydrolytic enzymes as described in Methods. After each incubation, the supernatant was separated and analysed for radioactivity and sugar (Table 4). Amylase released only $0.7 \%$ of the radioactivity when incubated with the labelled glucan, and no sugar was detected colorimetrically. The pellet from the $\alpha$-amylase incubation was then treated with Zymolyase (a mixture of endo- and exo- $(1 \rightarrow 3)-\beta$ glucanase). This incubation released $46 \%$ of the radioactivity, but the amount of sugar produced by this enzyme was only $0.65 \mathrm{mg}$ as measured by the phenol/sulphuric acid method. The addition of more Zymolyase and a further $24 \mathrm{~h}$ incubation only released an additional $0.5 \%$ of 
Table 5. Generation of oligosaccharides from $C$. albicans glucan by $(1 \rightarrow 3)-\beta$ - and $(1 \rightarrow 6)-\beta$ glucanases

C. albicans glucan (45000 c.p.m. $\mathrm{mg}^{-1}$ ) isolated from regenerated spheroplasts was degraded with $(1 \rightarrow 3)$ - $\beta$ - and $(1 \rightarrow 6)-\beta$-glucanases. In $(a)$ the glucan $(0.79 \mathrm{mg})$ was suspended in $0.5 \mathrm{ml} 0.2 \mathrm{M}$-sodium acetate buffer, pH 5.4, and incubated with Zymolyase $(0.3 \mathrm{mg})$ for $24 \mathrm{~h}$ at $37^{\circ} \mathrm{C}$. In (b) $0.27 \mathrm{mg}(1 \rightarrow 3)$ $\beta$-glucanase-treated glucan was suspended in $0.3 \mathrm{ml} 50 \mathrm{~mm}$-citrate buffer, $\mathrm{pH} 4.5$, and incubated with $(1 \rightarrow 6)$ - $\beta$-glucanase $(0.1 \mathrm{mg})$ for $24 \mathrm{~h}$ at $37^{\circ} \mathrm{C}$. In both $(a)$ and $(b)$ the solubilized material was analysed by descending paper chromatography in the solvent system n-propanol/ethyl acetate/water $(7: 1: 2$, by vol.). Components were identified with silver nitrate and corresponding areas of the chromatogram were removed and counted in Bray's scintillation fluid.

(a) $(1 \rightarrow 3)-\beta$-Glucanase

Identity

Origin Laminaripentose Laminaritetrose

Radioactivity (c.p.m.) 1530 180 260

Laminaritriose Laminaribiose 620 12640

Glucose

(b) $(1 \rightarrow 6)-\beta$-Glucanase

$\begin{array}{lccccc}\text { Identity } & \text { Origin } & \text { Gentiotetrose } & \text { Gentiotriose } & \text { Gentiobiose } & \text { Glucose } \\ \text { Radioactivity (c.p.m.) } & 3040 & 750 & 1330 & 3480 & 950\end{array}$

the radioactivity. Treatment of the Zymolyase-resistant material with $(1 \rightarrow 6)-\beta$-glucanase produced $0.85 \mathrm{mg}$ sugar by the phenol/sulphuric acid method, but only $10.6 \%$ of the radioactivity. Finally, the residue from $(1 \rightarrow 6)-\beta$-glucanase incubation was treated with chitinase, which released a further $41 \%$ of the radioactivity. The supernatant from the chitinase treatment contained $N$-acetylglucosamine $(0.58 \mathrm{mg})$. The phenol/sulphuric acid method, which does not detect $N$-acetylglucosamine (Herbert et al., 1971), was used to measure the remaining solubilized carbohydrates, and it was found that almost equal amounts of $\mathrm{N}$-acetylglucosamine and glucose equivalents were released by the chitinase. The sugar released from $(1 \rightarrow 3)-\beta$-glucan had a specific activity similar to that of the glucose in the regenerating medium (140000 c.p.m. $\mathrm{mg}^{-1}$; Table 4). The specific activity of the material released by $(1 \rightarrow 6)-\beta$ glucanase, however, was lower.

Table 5 shows the distribution of radioactivity in the different sugars produced by the action of Zymolyase [ $(1 \rightarrow 3)-\beta$-glucanase] and $(1 \rightarrow 6)-\beta$-glucanase on the isolated glucan. The $(1 \rightarrow 3)-\beta$ glucanase released oligosaccharides, with most radioactivity associated with laminaribiose and glucose. The $(1 \rightarrow 6)-\beta$-glucanase produced primarily gentiobiose and gentiotriose.

\section{DISCUSSION}

Glucose was the major product $(85 \%)$ after acid hydrolysis confirming the glucan nature of the isolated nets. A possible source of mannose in the hydrolysates is glucomannan complexes carried over from the original wall. Partial acid hydrolysis of $C$. albicans glucan nets revealed the presence of $\beta(1 \rightarrow 3)$ - and $\beta(1 \rightarrow 6)$-linked glucose residues. The presence of laminaritetrose and gentiotetrose provides evidence for chains of $\beta(1 \rightarrow 3)$ - and $\beta(1 \rightarrow 6)$-linked glucose residues. Since no mixed $\beta(1 \rightarrow 3) / \beta(1 \rightarrow 6)$ oligosaccharide was detected in the hydrolysate, it appeared that there are no intrachain $\beta(1 \rightarrow 3) / \beta(1 \rightarrow 6)$ linkages in the polysaccharide.

Hydrolysis of the methylated $C$. albicans glucan nets gave rise to four major $O$-methyl ethers (Table 3). The value of $9.5 \%$ for 2,3,4,6-tetra- $O$-methylglucose indicates a highly branched glucan. From the amount of the 2,4,6-and 2,3,4- derivatives, we conclude that $46 \%$ of the glucan is $\beta(1 \rightarrow 6)$-linked and $30 \%$ is $\beta(1 \rightarrow 3)$-linked. The presence of $9.5 \%$ of the $2,4-\mathrm{di}$ - $O$-methylglucose confirmed the highly branched nature of the glucan. The 4,6-di-O-methylglucose probably originated from undermethylation. These data can be accommodated by either a highly branched mixed $\beta(1 \rightarrow 3) / \beta(1 \rightarrow 6)$ glucan or two different branched glucans, one a $\beta(1 \rightarrow 3)$ and the other a $\beta(1 \rightarrow 6)$ polymer.

The periodate oxidation data are also in good agreement with the methylation analysis. A glucan of the composition shown in Table 3 would, theoretically, consume 0.84 mol periodate and produce $0.42 \mathrm{~mol}$ formic acid per mol anhydroglucose. These values are close to the values of 0.88 and 0.37 obtained experimentally for the periodate consumption and formic acid 
production respectively. Clearly these glucan nets contain highly branched $\beta(1 \rightarrow 3)$ - and $\beta(1 \rightarrow 6)$-linked glucose residues.

Two well-characterized polysaccharides, laminarin and pustulan, were subjected to periodate oxidation analysis to confirm the validity of the method. Theoretical values for periodate consumed and formic acid produced per mol anhydrohexose are 1.96 and $0.93 \mathrm{~mol}$ respectively for the pustulan and 0.17 and $0.09 \mathrm{~mol}$ respectively for laminarin, on the basis of the methylation results. Thus, the values for periodate consumption and formic acid production for pustulan were in excellent agreement with the theoretical values but for laminarin they were higher than the theoretical values. Ram et al. (1981) pointed to the mannose and mannitol present in laminarin to account for these higher values.

Enzymes of known specificity are used in glucan analysis and the products give information on the nature of linkage hydrolysed and, also, on the structure of the resistant residue. However, as pointed out by Duffus et al. (1982), the lack of specificity of the enzymes available limits the usefulness of this approach. For some of the glucanases it has been shown that the specificity is controlled not by the linkage hydrolysed but by the adjacent linkage. For example, some endo$(1 \rightarrow 3)$ - $\beta$-glucanases may hydrolyse either $(1 \rightarrow 4)$ or $(1 \rightarrow 6)$ linkages in substrates containing both $\beta(1 \rightarrow 3)$ and a second type of glycosidic linkage (Duffus et al., 1982). Thus, the specificity of the enzymes used in this study was tested. The four enzyme preparations used to study the glucan nets were $\alpha$-amylase, Zymolyase [( $1 \rightarrow 3)$ - $\beta$-glucanase], $(1 \rightarrow 6)-\beta$-glucanase and chitinase.

$\alpha$-Amylase, when incubated with radioactive glucan, released only $0.7 \%$ of the radioactivity and undetectable amounts of sugar. This result, with the methylation data, confirmed the absence of $\alpha(1 \rightarrow 4)$ linkages in the glucan preparation. The small amount of radioactivity released could have arisen from contamination by intracellular glycogen.

Zymolyase is a mixture of exo- and endo-( $1 \rightarrow 3)-\beta$-glucan hydrolase activities and has a specificity for chains of $(1 \rightarrow 3)$ - $\beta$-linked residues (Kitamura \& Yamamoto, 1972; Ram et al., 1981). This enzyme is free of $\alpha$ - and $(1 \rightarrow 4)-\beta-,(1 \rightarrow 2)-\beta$ - and $(1 \rightarrow 6)-\beta$-glucanase activities (Kitamura \& Yamamoto, 1972; P. K. Gopal, unpublished). When Zymolyase was incubated with the $C$. albicans glucan, $46 \%$ of the radioactivity was released from the nets and $23 \%$ of the total carbohydrate was solubilized. These data indicate the presence of chains of $\beta(1 \rightarrow 3)$-linked glucose residues in the glucan. Laminaribiose and glucose were found to be the major products in the enzyme hydrolysates and the absence of gentio-oligosaccharides in the solubilized material rules out the possibility of intrachain $\beta(1 \rightarrow 6)$-linked glucose residues in the $\beta(1 \rightarrow 3)$ glucan. This result is also supported by the results of the partial acid hydrolysis. The production of laminaribiose and glucose as the end products of the Zymolyase hydrolysis is at variance with the results of Kitamura \& Yamamoto (1972) who reported laminaripentose as the minimum product of the hydrolysis. This disparity is probably due to the different incubation time of $2 \mathrm{~h}$ compared to $24 \mathrm{~h}$ in the present study. Further incubation of the Zymolyase-resistant material with fresh enzyme did not result in any further hydrolysis of the glucan. This result could mean either that there were no further $(1 \rightarrow 3)$ - $\beta$-glucanase-susceptible linkages left in the glucan or that the physical state of the molecule was unfavourable for the enzyme hydrolysis (Rees, 1973). Studies with cellulases (Shepherd et al., 1981) and with purified $\beta(1 \rightarrow 3)$ glucans (Fleet \& Manners, 1977) have shown that the physical state of the substrate can limit enzyme action. The specific activity of the sugars released by Zymolyase ( 94450 c.p.m. per mg carbohydrate) indicated that the majority of the $\beta(1 \rightarrow 3)$ glucan was synthesized de novo during the regeneration of the spheroplasts.

$(1 \rightarrow 6)-\beta$-Glucanase solubilized $30 \%$ of the $(1 \rightarrow 3)$ - $\beta$-glucanase-resistant material. However, only $11 \%$ of the radioactivity was released by this enzyme, which indicates that before regeneration was initiated, the spheroplasts contained a substantial amount of $\beta(1 \rightarrow 6)$ glucan. The presence of $\beta(1 \rightarrow 6)$-linkages in the spheroplasts prepared with Zymolyase is not an unexpected result.

$(1 \rightarrow 6)-\beta$-Glucanase hydrolysis produced gentio-oligosaccharides but $27 \%$ of the radioactivity remained at the origin of the chromatogram. It is likely that oligosaccharides with a degree of polymerization higher than pentasaccharide are present in the hydrolysate. None of the oligosaccharides from the laminarin series (up to a degree of polymerization of 5) were detected 
in the hydrolysate and this confirmed that the glucan consisted of chains of $\beta(1 \rightarrow 6)$-linked glucose residues which did not contain intrachain $\beta(1 \rightarrow 3)$ linkages.

Chitinase released the residual radioactivity from the $(1 \rightarrow 6)-\beta$ - and $(1 \rightarrow 3)-\beta$-glucanaseresistant material and glucose and $N$-acetylglucosamine were detected in equimolar amounts. There was no residual net. The chitinase contained glucanase activity (M. G. Shepherd, unpublished) and it is suggested that the hydrolysis of chitin exposed residual glucan susceptible to glucanase degradation. The data suggest either a physical entrapment of glucan with the chitin, or a linkage between the polymers. Yeast wall structure has been reviewed by Cabib et al. (1982). Most $(90 \%)$ of the chitin is associated with bud scars (Bacon et al., 1966), and the remainder appears to be associated with an innermost insoluble branched $\beta(1 \rightarrow 3) / \beta(1 \rightarrow 6)$ glucan fraction (Sietsma \& Wessels, 1981).

Manners et al. $(1973 a, b)$ have shown that the glucan fraction of Saccharomyces cerevisiae is composed of heterogeneous branched glucans; $\beta(1 \rightarrow 3)$ is the predominant linkage in one polymer, and $\beta(1 \rightarrow 6)$ in the other. By analogy and from the data presented here, we suggest that in the cell wall of $C$. albicans there are three types of glucan: a mixed $\beta(1 \rightarrow 3) / \beta(1 \rightarrow 6)$ glucan complexed to chitin adjacent to the plasma membrane, and two highly branched glucans with either $\beta(1 \rightarrow 3)$ or $\beta(1 \rightarrow 6)$ linkages as the predominant structure. It has been shown that the alkali-insoluble residue from protoplast nets resembles microfibrils found in whole cells (Kreger \& Kopecká, 1975).

This work was supported by grants from the Medical Research Council of New Zealand. P. G. was the recipient of a New Zealand University Grants Committee Scholarship.

\section{REFERENCES}

Aspinall, G. O. \& Ferrier, R. J. (1957). A spectrophotometric method for the determination of periodate consumed during the oxidation of carbohydrates. Chemistry and Industry 1216.

Bacon, J. S. D., Davidson, E. D., Jones, D. \& TAYLOR, I. F. (1966). The location of chitin in the yeast cell wall. Biochemical Journal 101, $36 \mathrm{C}-38 \mathrm{C}$.

Bishop, C. T., Blank, F. \& Gardner, P. E. (1960). The cell wall polysaccharides of Candida albicans: glucan, mannan and chitin. Canadian Journal of Chemistry 38, 869-881.

Borchardt, L. G. \& Piper, C. V. (1970). A gas chromatographic method for carbohydrates as alditol-acetates. Tappi 53, 257-260.

Bouveng, H. O. \& LindBerG, B. (1965). Hydrolysis of methylated polysaccharides. Methods in Carbohydrate Chemistry 5, 296-298.

CABIB, E., RoberTS, R. \& Bowers, B. (1982). Synthesis of the yeast cell wall and its regulation. Annual Review of Biochemistry 51, 763-793.

Cassone, A., Kerridge, D. \& Gale, E. F. (1979). Ultrastructural changes in the cell wall of Candida albicans following cessation of growth and their possible relationship to the development of polyene resistance. Journal of General Microbiology 110, 339349.

ConRaD, H. E. (1972). Methylation of carbohydrates with methylsulfinyl anion and methyl iodide in dimethylsulfoxide. Methylation of Aerobacter aerogenes $\mathrm{A} 3(\mathrm{~S} 1)$ capsular polysaccharide and 3-O- $\alpha-\mathrm{D}-$ glucopyranosyluronic acid-D-mannose. Methods in Carbohydrate Chemistry 6, 361-364.
Dawson, R. M. C., Elliot, D. C., Elliot, W. W. \& JONES, K. M. (1959). In Data for Biochemical Research, p. 236. Oxford: Oxford University Press.

Dubois, M., Gilles, K. A., Hamilton, J. K., Rebers, P. A. \& SMITH, F. (1956). Colorimetric method for determination of sugars and related substances. Analytical Chemistry 28, 350-356.

Duffus, J. H., Levi, C. \& Manners, D. J. (1982). Yeast cell wall glucans. Advances in Microbial Physiology 23, 151-178.

Fleet, G. H. \& Manners, D. J. (1977). The enzymic degradation of an alkali-soluble glucan from the cell walls of Saccharomyces cerevisiae. Journal of General Microbiology 98, 315-327.

Gopal, P., Sullivan, P. A. \& Shepherd, M. G. (1984). Metabolism of $\left[{ }^{14} \mathrm{C}\right]$ glucose by regenerating spheroplasts of Candida albicans. Journal of General Microbiology 130, 325-335.

HAKOMORI, S.-I. (1964). A rapid permethylation of glycolipid and polysaccharide catalyzed by methylsulfinyl carbanion in dimethylsulfoxide. Journal of Biochemistry 55, 205-208.

HAY, G. W., Lewis, B. A. \& SMITH, F. (1965). Periodate oxidation of polysaccharides: general procedures. Methods in Carbohydrate Chemistry 5, 357-360.

Herbert, D., Phillips, R. J. \& Strange, R. E. (1971). Chemical analysis of microbial cells. Methods in Microbiology 5B, 272-277.

Kitamura, K. \& Yamamoto, Y. (1972). Purification and properties of an enzyme, Zymolyase, which lyses viable yeast cells. Archives of Biochemistry and Biophysics 153, 403-406. 
KREGeR, D. R. \& KoPECKÁ, M. (1975). On the nature and formation of the fibrillar nets produced by protoplasts of Saccharomyces cerevisiae in liquid media: an electronmicroscopic, $\mathrm{X}$-ray diffraction and chemical study. Journal of General Microbiology 92, 207-220.

Manners, D. J., Masson, A. J. \& Patterson, J. C. $(1973 a)$. The structure of a $\beta$ - $(1 \rightarrow 3)$-D-glucan from yeast cell walls. Biochemical Journal 135, 19-30.

Manners, D. J., Masson, A. J., Patterson, J. C., Bjorndal, H. \& LindberG, B. $(1973 b)$. The structure of a $\beta-(1 \rightarrow 6)$-D-glucan from yeast cell walls. Biochemical Journal 135, 31-36.

Peat, S., Whelan, W. J. \& Edwards, T. E. (1958). Polysaccharides of baker's yeast. Part II. Yeast glucan. Journal of the Chemical Society 38623868.

Poulter, R., JefFery, K., Hubbard, M. J., Sullivan, P. A. \& Shepherd, M. G. (1981). Parasexual genetic analysis of Candida albicans by spheroplast fusion. Journal of Bacteriology 146, 833-840.

Ram, S., Beyer, R., Shepherd, M. G. \& Sullivan, P. A. (1981). Isolation and analysis of neutral glucans from Ecklonia radiata and Cystophora scalaris. Carbohydrate Research 96, 95-104.

ReEs, D. A. (1973). Polysaccharide conformation. In Carbohydrates (MTP International Review of Science: Organic Chemistry, series I, vol. 7), pp. 251-283. Edited by G. O. Aspinall. London: Butterworths.
Reissig, J. L., Strominger, J. L. \& Leloir, L. F. (1955). A modified colorimetric method for the estimation of $\mathrm{N}$-acetylamino sugars. Journal of Biological Chemistry 217, 959-966.

ScotT, J. \& Schekman, R. (1980). Lyticase: endoglucanase and protease activities that act together in yeast cell lysis. Journal of Bacteriology 142, 414-423.

ShePherd, M. G. \& Sullivan, P. A. (1976). The production and growth characteristics of yeast and mycelial forms of Candida albicans in continuous culture. Journal of General Microbiology 93, 361-370.

Shepherd, M. G., Tong, C. C. \& Cole, A. L. (1981). Substrate specificity and mode of action of the cellulases from the thermophilic fungus Thermoascus aurantiacus. Biochemical Journal 193, 67-74.

Sietsma, J. H. \& Wessels, J. G. H. (1981). Solubility of $(1 \rightarrow 3)-\beta-D /(1 \rightarrow 6)-\beta$-D-glucan in fungal walls: importance of presumed linkage between glucan and chitin. Journal of General Microbiology 125, 209-212.

Sullivan, P. A., Chiew, Y. Y., Molloy, C., TempleTON, M. D. \& SHEPHERD, M. G. (1983). An analysis of the metabolism and cell wall composition of Candida albicans during germ-tube formation. Canadian Journal of Biochemistry 29, 1514-1525.

YU, R. T., BISHop, C. T., COOPER, F. P., HASENCleVER, H. F. \& BLANK, F. (1967). Structural studies of mannans from Candida albicans (Serotypes A and B), Candida parapsilosis, Candida stellatoidea and Candida tropicalis. Canadian Journal of Chemistry 45, 2205-2211. 